\title{
Fertilizaçao de liberação lenta no crescimento de mudas de paricá em viveiro
}

Uberson Boaretto Rossa ${ }^{1}$, Alessandro Camargo Angelo ${ }^{1}$, Antonio Carlos Nogueira ${ }^{1}$, Itamar Antonio Bognola ${ }^{2}$, Danielle Janaina Westphalen Pomianoski ${ }^{3}$, Philipe Ricardo Casemiro Soares ${ }^{4}$, Lizy Tank Sampaio Barros ${ }^{1}$

${ }^{1}$ Universidade Federal do Paraná, Departamento de Ciencias Florestais, Av. Prefeito Lothário Meissner, 3400, CEP 80210-170, Curitiba, PR, Brasi

2Embrapa Florestas, Estrada da Ribeira, km 111, CP 319, CEP 83411-000, Colombo, PR, Brasil

${ }^{3}$ Universidade Tecnológica Federal do Paraná, Av. Pref. Lothário Meissner, 900, Campus III, CEP 80210170, Curitiba, PR, Brasil

${ }^{4}$ Universidade do Estado de Santa Catarina, Centro Agroveterinário, Av. Luiz de Camões, 2090, CEP 88520-000, Lages, SC, Brasil

*Autor correspondente:

boarettorossa@gmail.com

Termos para indexação:

Schizolobium parahyba var. amazonicum

Qualidade de mudas florestais

Nutrição

\section{Index terms:}

Schizolobium parahyba var. amazonicum

Quality forest seedlings

Nutrition

Histórico do artigo:

Recebido em 31/08/2012

Aprovado em 20/09/2013

Publicado em 30/09/2013

doi: 10.4336/2013.pfb.33.75.429
Resumo - A utilização da fertilização de liberação lenta (FLL) pode contribuir para a obtenção de mudas de melhor qualidade, diante de um setor habituado à utilização de fertilizantes comerciais. O objetivo desse trabalho foi avaliar doses de FLL no crescimento de mudas de paricá e a comparar o custo na produção do uso de adubo convencional em relação ao custo com FLL. O delineamento experimental foi inteiramente casualizado com seis tratamentos em quatro repetições de 40 plantas, sendo um controle e os demais com adição de diferentes doses de FLL por $\mathrm{m}^{3}$ de substrato utilizado para a produção de mudas. Decorridos 81 dias da semeadura, foram analisadas as variáveis altura total, diâmetro do colo, biomassa fresca da parte aérea, biomassa seca da parte aérea, biomassa seca da raiz, biomassa seca total e dose de máxima eficiência técnica. As mudas de paricá responderam positivamente ao uso do FLL, apresentando melhores padrões nos parâmetros de interesse em doses variando de 8,65 a $12,07 \mathrm{~kg} \mathrm{~m}^{-3}$ em relação ao controle sem FLL. Os custos de aquisição foram superiores quando comparados à adubação convencional, sendo necessária uma analise econômica e silvicultural para inferir sobre a viabilidade do seu uso na produção e implantação de plantios.

\section{Slow release fertilization on growth of paricá tree seedlings in nursery}

\begin{abstract}
The use of slow release fertilizer (SRF) can contribute to obtain better seedlings before an industry accustomed to the use of commercial fertilizers. This work aimed to evaluate doses of SRF on the growth of paricá tree seedlings and to compare the cost of conventional fertilizer use in relation to the cost involved in producing with SRF. The experimental design was completely randomized with 6 treatments and 4 replications of 40 plants, with one control and the other treatments with the addition of different doses of SRF per $\mathrm{m}^{3}$ of substrate used for seedlings production . After 81 days of sowing, it was analyzed total height, stem diameter, shoot fresh and dry weights, root dry weight, total biomass and maximum level of technical efficiency. Paricá tree seedlings responded positively to the use of SRF, presenting best results in parameters at doses ranging from 8.65 to $12.07 \mathrm{~kg} \mathrm{~m}^{-3}$ compared to control without SRF. Acquisition costs were higher when compared to conventional fertilization, requiring an economical and forestry analysis to infer on the feasibility of its use in the production and establishment of stands.
\end{abstract}




\section{Introdução}

As espécies florestais nativas podem apresentar potencial de uso para a produção madeireira e multiprodutos da floresta, de modo que há uma demanda crescente por estudos silviculturais dessas espécies, a começar pela produção de mudas de qualidade para o estabelecimento de plantios comerciais.

A informação disponível sobre aspectos silviculturais é limitada para muitas espécies florestais de interesse comercial, especialmente para nativas. Dentre elas, destaca-se o Schizolobium parahyba var. amazonicum, mais conhecido como paricá, de ocorrência natural no norte do Brasil (Acre, Amazonas, Mato Grosso, Pará e Rondônia), Bolívia, Colômbia, Equador, Honduras e Peru. Essa espécie tem se mostrado de grande interesse comercial, com plantios concentrados nos Estados do Pará e Maranhão (Carvalho, 2003).

Tendo por base os dados do Centro de Pesquisas do Paricá no Brasil, a área plantada passou de 80.180 ha em 2008 para a 85.470 ha em 2010 (ANUÁRIO..., 2011).

Mudas de baixo padrão de qualidade apresentam menores incrementos no crescimento, o que implica na redução dos ganhos de volume de madeira, desenvolvendo-se com tendência de menor uniformidade, bifurcações do fuste e, consequentemente, depreciação do valor da floresta (Carneiro, 1995). Assim, torna-se necessário produzir mudas de qualidade em viveiros florestais, utilizando substratos de boa qualidade físicoquímica e aliando-se à uma adubação equilibrada, a qual possa adequadamente atender às demandas nutricionais das plantas na fase juvenil (Gonçalves \& Poggiani, 1996).

Para Carneiro (1995), os substratos destinados à produção de mudas devem ser férteis e livre de patógenos, com vistas a favorecer a germinação e o desenvolvimento das mudas. Desta forma, recomenda-se a adição de fertilizantes minerais ao substrato, quando o mesmo for de baixa fertilidade, para promover o suprimento dos nutrientes necessários, economizando-se tempo no processo de produção das mudas. A formulação e a dosagem utilizadas são variáveis em função do tipo de substrato utilizado e da espécie a ser produzida, sendo recomendada a realização de uma análise química do substrato e, caso necessário, proceder à correção da acidez e elevação do teor de nutrientes disponíveis (Wendling et al., 2006).
Lanza et al. (1996a; 1996b) e Marques et al. (2004), demonstraram os efeitos negativos no crescimento inicial do paricá quando da omissão de macronutrientes e de micronutrientes, bem como os sintomas de deficiências nutricional em mudas dessa espécie.

Dentre as técnicas de fertilização do substrato em viveiros florestais, o emprego de fertilizantes de liberação lenta (FLL) representa uma das mais viáveis e racionais alternativas (Bockman \& Olfs, 1998; Shaviv, 1999). A utilização de FLL reduz problemas da aplicação de doses excessivas, a plasmólise dos tecidos tenros da muda pelo efeito salino de determinados fertilizantes e a perdas de nutrientes por lixiviação (Barbizan et al., 2002), além de reduzir a mortalidade de plantas por choque de plantio (Lang, 1998).

A principal desvantagem dos FLL é o custo superior às fontes de fertilizantes comerciais tradicionais, requerendo a adequação e o parcelamento das doses para otimizar o uso do insumo e garantir a produção econômica de mudas (Scivittaro et al., 2004).

O presente trabalho teve como objetivo avaliar o crescimento inicial de mudas de paricá submetidas a doses de FLL, bem como discutir às questões econômicas relacionadas ao uso desse insumo.

\section{Material e métodos}

O presente trabalho foi realizado durante o período de dezembro de 2007 a fevereiro de 2008, sendo conduzido em viveiro de produção de mudas localizado sob as coordenadas geográficas: 27¹1'16"S e 49³9'37'W, e altitude de 701,54 m, instalado no Instituto Federal de Educação Ciência e Tecnologia, no município de Rio do Sul, SC.

Foram utilizadas sementes provenientes de coletas realizadas na reserva indígena Parakanã, localizada no município de Tucuruí (0346’04” S, 4940’22” O), sudeste do Estado do Pará.

Antes do plantio, as sementes foram submetidas a tratamento de quebra de dormência, utilizando o método de escarificação mecânica com esmerilhamento na parte oposta à micrópila e, na sequência, realizou-se a imersão do material em água a $80^{\circ} \mathrm{C}$, por $24 \mathrm{~h}$.

As sementes foram semeadas em tubetes de $180 \mathrm{~cm}^{3}$, utilizando-se uma mistura de substrato florestal a base de casca de pinus (60\%), composto orgânico peneirado (30\%) e vermiculita de granulometria média $(10 \%)$. Suas características químicas e físicas estão apresentadas na Tabela 1 . 
Tabela 1. Análise química e física das matérias primas utilizadas no substrato do experimentos de produção de mudas de Schizolobium parahyba var. amazonicum com dosagens crescentes de fertilizante de liberação lenta, em Rio do Sul, SC.

\begin{tabular}{|c|c|c|c|c|c|}
\hline \multicolumn{2}{|c|}{ Substrato florestal } & \multicolumn{2}{|c|}{ Composto orgânico } & \multicolumn{2}{|c|}{ Fertilizante de liberação lenta } \\
\hline $\mathrm{pH}\left(\mathrm{H}_{2} \mathrm{O}\right)$ & $\begin{array}{c}5,8 \\
(+/-0,5)\end{array}$ & $\mathrm{pH}\left(\mathrm{H}_{2} \mathrm{O}\right)$ & 6,3 & $\mathrm{~N}(\%)$ & 13 \\
\hline & & Índice (SMP) & 6,8 & & \\
\hline \multirow[t]{3}{*}{$\begin{array}{l}\text { Capacidade de retenção } \\
\text { de água }(\%)\end{array}$} & 150 & $\mathrm{Ca}\left(\mathrm{cmol}_{\mathrm{c}} \mathrm{dm}^{3}\right)$ & 7,0 & $\mathrm{P}_{2} \mathrm{O}_{5}\left[\right.$ Sol. em CNA $\left.+\mathrm{H}_{2} \mathrm{O}\right](\%)$ & 6 \\
\hline & & $\operatorname{Mg}\left(\mathrm{cmol}_{\mathrm{c}} \mathrm{dm}^{3}\right)$ & 4,4 & $\mathrm{~K}_{2} \mathrm{O}(\%)$ & 16 \\
\hline & & $\mathrm{Al}\left(\mathrm{cmol}_{\mathrm{c}} \mathrm{dm}^{3}\right)$ & 0,0 & $\mathrm{MgO}(\%)$ & 1,40 \\
\hline \multirow[t]{2}{*}{ Umidade (\%) } & até $50 \%$ & $\mathrm{H}+\mathrm{Al}\left(\mathrm{cmol}_{\mathrm{c}} \mathrm{dm}^{3}\right)$ & 1,7 & $\mathrm{~S}(\%)$ & 10 \\
\hline & & CTC $\left(\mathrm{cmol}_{\mathrm{c}} \mathrm{dm}^{3}\right)$ & 16,5 & $\mathrm{~B}(\%)$ & 0,02 \\
\hline \multirow[t]{3}{*}{ Densidade $\left(\mathrm{kg} \mathrm{m}^{-3}\right)$} & 450 & Saturação Al (\%) & 0,0 & $\mathrm{Cu}(\%)$ & 0,05 \\
\hline & & Saturação Base (\%) & 89,5 & $\mathrm{Fe}(\%)$ & 0,26 \\
\hline & & M.O. (\%) & 7,8 & Mn (\%) & 0,06 \\
\hline \multirow[t]{3}{*}{$\begin{array}{l}\text { Condutividade elétrica } \\
(\mathrm{mS} \mathrm{cm})\end{array}$} & $\begin{array}{c}2,6 \\
(+/-0,3)\end{array}$ & Argila (\%) & 27 & Mo (\%) & 0,015 \\
\hline & & $\mathrm{P}\left(\mathrm{mg} \mathrm{dm}^{3}\right)$ & 560 & Diâmetro grânulos (mm) & $\begin{array}{c}1,5 \mathrm{a} \\
2,8\end{array}$ \\
\hline & & $\left.\mathrm{K}(\mathrm{mg} \mathrm{dm})^{3}\right)$ & 1.160 & Peso de 1.000 grãos (g) & 9,58 \\
\hline
\end{tabular}

Para os tratamentos utilizou-se fertilizante de liberação lenta de marca comercial Basacote ${ }^{\circledR}$ Mini 6M na formulação $13-6-16\left(\mathrm{~N}-\mathrm{P}_{2} \mathrm{O}_{5}-\mathrm{K}_{2} \mathrm{O}\right)$.

Amistura desses insumos, bem como a homogeneização das doses testadas ao substrato, foi realizada com betoneira, por um período de 5 min.

Os tubetes foram preenchidos e logo submetidos à mesa compactadora por 10 segundos, objetivando densidade uniforme do substrato. Após a semeadura, as bandejas com os tubetes foram mantidas com nível de sombreamento de $50 \%$ e a umidade do substrato foi controlada por sistema de irrigação por micro aspersão.

O delineamento experimental utilizado foi inteiramente casualizado, com seis tratamentos em quatro repetições, tendo 40 plantas como unidade experimental. Os tratamentos foram: T1 - $0 \mathrm{~kg}$ (controle); T2 - $2 \mathrm{~kg}$; T3 $-4 \mathrm{~kg}$; T4 - $6 \mathrm{~kg}$; T5 - $8 \mathrm{~kg}$ e T6 - $10 \mathrm{~kg}$ de FLL por $\mathrm{m}^{3}$ de substrato.

Decorridos 81 dias da semeadura, coletaram-se dados de altura $(\mathrm{cm})$ da parte aérea da muda, medindo-se as mesmas com régua, do nível do substrato do tubete até o ápice e o diâmetro do colo (mm) medido com paquímetro, a $0,5 \mathrm{~cm}$ do solo. Em seguida, determinou-se a biomassa fresca da parte aérea com balança de precisão milesimal. As raízes foram destorroadas e lavadas sob peneiras de $2 \mathrm{~mm}$ para evitar possíveis perdas. As amostras da parte aérea e das raízes foram acondicionadas em sacos de papel pardo e secas em estufa a $60{ }^{\circ} \mathrm{C}$, com ventilação forçada até obtenção do peso constante.

Foram analisados os parâmetros biométricos de altura total $(\mathrm{H})$, diâmetro do colo (DC), biomassa fresca da parte aérea (BFPA) e biomassa seca da parte aérea (BSPA), biomassa seca da raiz (BSR), biomassa seca total (BST). Os índices de qualidade de muda analisados foram a relação entre altura e diâmetro do colo (H/DC) e o índice de qualidade de Dickson (IQD) (Dickson et al., 1960). Após verificação dessas variáveis foi calculada a dose de máxima eficiência técnica (DMET) a partir da equação de regressão linear para cada variável estudada em função da dose de FLL aplicada.

Os dados foram submetidos à análise de variância (ANOVA) e as médias comparadas pelo teste de Tukey ao nível de $5 \%$ de probabilidade. 


\section{Resultados e discussão}

A aplicação de FLL levou a ganhos significativos de crescimento das mudas se comparado às plantas não fertilizadas (controle). As diferentes dosagens influenciaram significativamente ( $5 \%$ de probabilidade), nas variáveis avaliadas (Tabela 2).

O tratamento T5, com dose de $8 \mathrm{~kg} \mathrm{~m}^{-3}$ de FLL mostrou resultado superior aos demais tratamentos, quando analisadas as variáveis altura, diâmetro, biomassa fresca e seca da parte aérea. Porém, em relação à BSR, BST, H/ DC, nota-se que o T6 apresentou melhores resultados, de modo que a dose de $10 \mathrm{~kg} \mathrm{~m}^{-3}$ de FLL indica haver maior taxa de sobrevivência das mudas em campo, também observado por Almeida et al. (2005).

Os valores para IQD variaram entre 0,29 e 0,58 (Tabela 2). A maior média foi observada no tratamento T6. Estabelecendo-se como padrão para o índice de qualidade de Dickson, o valor mínimo de 0,20 , conforme recomendação de Hunt (1990) observa-se que os tratamentos TO, T1, T2, T3 e T4 obtiveram os menores valores, porém acima do valor mínimo recomendado.

Também Hunt (1990), observando a qualidade de mudas de algumas espécies como Pseudotsuga menziessi e Picea abies, verificou que as mudas que obtiveram o índice de qualidade de Dickson com valores superiores a 0,20 seriam consideradas de boa qualidade.

Conforme Fonseca (2000), o manejo das mudas no viveiro pode permitir que se atinja o valor mínimo desejado. A relação entre as variáveis de crescimento e o IQD em mudas de eucalipto (Eucalyptus grandis) e pinus (Pinus elliottii) foram analisadas por Binotto (2007), que concluiu que o IQD foi eficiente para indicar qualidade de mudas, pois apresentou boa correlação com as variáveis estudadas para as duas espécies. Vale ressaltar que ensaio de calibração do IQD para as espécies de interesse configura em importante necessidade para as investigações de qualidade de muda.

Rossa et al. (2011), em um estudo com mudas de Araucaria agustifolia, mostram que para a variável altura da parte aérea $(\mathrm{H})$, a dose de $9 \mathrm{~kg} \mathrm{~m}^{-3}$ de FLL, teve o maior efeito.

Binotto (2007) aponta que dentre as variáveis avaliadas, o DC é o parâmetro mais propício para indicar qualidade de muda, baseado no seu maior grau de relação com o IQD. Portanto, pode-se inferir que a dose de $8 \mathrm{~kg} \mathrm{~m}^{-3}$ é a mais indicada, quando busca-se a robustez do coleto em mudas de paricá. O menor valor foi de 3,94 mm, mais uma vez verificado no tratamento sem adição de FLL (controle).

Moraes Neto et al. (2003a), também em trabalho de fertilização com FLL, porém com substrato base distinto, em mudas de mutambo (Guazuma ulmifolia), canafístula (Peltophorum dubium) e eucalipto (Eucalyptus grandis), recomendam a utilização de $6,42 \mathrm{~kg} \mathrm{~m}^{-3}$ de Basacote no substrato. No entanto, Moraes Neto et al. (2003b), em trabalho com mutambo (Guazuma ulmifolia), capixingui (Croton floribundus), canafístula (Peltophorum dubium), pau-d'alho (Gallesia integrifolia) e cabreúva (Myroxylon peruiferum), concluíram que doses de FLL entre 3,2 e 4,8 $\mathrm{kg} \mathrm{m}^{-3}$ foram as que resultaram em mudas de melhor qualidade para essas espécies estudadas.

Tabela 2. Médias das variáveis altura total (H), diâmetro do colo (DC), biomassa fresca da parte aérea (BFPA), biomassa seca da parte aérea (BSPA), biomassa seca da raiz (BSR), biomassa seca total (BST), relação altura e diâmetro do colo (H/DC) e índice de qualidade de Dickson (IQD) das mudas de Schizolobium parahyba var. amazonicum.

\begin{tabular}{|c|c|c|c|c|c|c|c|c|}
\hline \multirow{3}{*}{$\begin{array}{c}\text { Dose }\left(\mathrm{kg} / \mathrm{m}^{3}\right) \\
\text { tratamento }\end{array}$} & \multicolumn{6}{|c|}{ Parâmetros biométricos } & \multicolumn{2}{|c|}{ Índices de qualidade } \\
\hline & \multirow{2}{*}{$\begin{array}{c}\mathbf{H} \\
-\mathrm{cm}-\end{array}$} & \multirow{2}{*}{$\begin{array}{c}\text { DC } \\
-\mathrm{mm}-\end{array}$} & BFPA & BSPA & BSR & BST & H/DC & IQD \\
\hline & & & \multicolumn{4}{|c|}{---------------------- g --------------------- } & & \\
\hline $0(\mathrm{~T} 1)$ & $24,64 \mathrm{c}$ & $3,94 b$ & $3,80 \mathrm{c}$ & $0,84 \mathrm{c}$ & $1,16 b$ & $2,00 \mathrm{~d}$ & $6,31 \mathrm{a}$ & $0,29 \mathrm{c}$ \\
\hline $2(\mathrm{~T} 2)$ & $29,73 b$ & $4,34 \mathrm{ab}$ & $6,11 b$ & $1,43 b$ & $1,45 b$ & $2,88 \mathrm{bc}$ & $6,88 \mathrm{a}$ & $0,36 \mathrm{bc}$ \\
\hline $4(\mathrm{~T} 3)$ & $29,24 b$ & $4,10 \mathrm{~b}$ & $5,80 \mathrm{~b}$ & $1,34 b$ & $1,14 \mathrm{~b}$ & $2,48 \mathrm{~cd}$ & $7,15 \mathrm{a}$ & $0,29 \mathrm{c}$ \\
\hline $6(\mathrm{~T} 4)$ & $30,47 b$ & $4,26 \mathrm{ab}$ & $6,48 \mathrm{ab}$ & $1,38 b$ & $1,41 b$ & $2,79 \mathrm{bcd}$ & $7,16 \mathrm{a}$ & $0,34 \mathrm{bc}$ \\
\hline 8 (T5) & $33,37 \mathrm{a}$ & $4,90 \mathrm{a}$ & $7,60 \mathrm{a}$ & $1,77 \mathrm{a}$ & $1,75 b$ & $3,52 b$ & $6,84 a$ & $0,45 b$ \\
\hline $10(\mathrm{~T} 6)$ & $31,62 \mathrm{ab}$ & $4,41 \mathrm{ab}$ & $6,13 b$ & $1,45 b$ & $3,01 \mathrm{a}$ & $4,46 \mathrm{a}$ & $7,18 \mathrm{a}$ & $0,58 \mathrm{a}$ \\
\hline $\mathrm{CV}(\%)$ & 3,68 & 7,23 & 10,19 & 8,56 & 21,16 & 11,66 & 6,86 & 14,43 \\
\hline
\end{tabular}

*Médias seguidas pela mesma letra na coluna não diferem entre si pelo teste de Tukey $(\mathrm{p}>0,05)$. 
As doses de máxima eficiência técnica (DMET) (Figura 1) apresentaram valores distintos dentro dos diferentes parâmetros avaliados. A dose estimada por regressão para atingir maior incremento em altura $(\mathrm{H})$ foi de $8,65 \mathrm{~kg} \mathrm{~m}^{-3}$ de FLL. Para a variável diâmetro de coleto (DC) estimou-se uma dose de $12,07 \mathrm{~kg} \mathrm{~m}^{-3}$ de FLL representando o valor em que as mudas desta espécie apresentam maior incremento para esta variável.

Os resultados obtidos para a variável que relaciona $\mathrm{H} /$ DC mostraram que não houve diferença estatística entre os tratamentos com índices entre 6,31 a 7,18. Jose et al. (2009) consideram que mudas de espécies florestais de alta qualidade devem apresentar índices H/DC menores que 10, e quando atendem esse índices, apresentam maior sobrevivência após o plantio.

$\mathrm{O}$ efeito dos diferentes tratamentos sobre a BFPA apresentou influência significativa. $\mathrm{O}$ tratamento com $8 \mathrm{~kg} \mathrm{~m}^{-3}$ foi superior em relação a essa variável (Figura 2).

Já em relação à produção de BSPA, BSR e BST, verificou-se que houve diferenças significativas entre os tratamentos com a aplicação do FLL, e o tratamento com $8 \mathrm{~kg} \mathrm{~m}^{-3}$ também apresentou superioridade, com $1,78 \mathrm{~g}$. As maiores produções nas variáveis BSR e BST foram obtidas no tratamento $10 \mathrm{~kg} \mathrm{~m}^{-3}$, correspondendo a 3,01 g e 4,45 g (Figura 2).

Em outro estudo, Rossa et al. (2011) obteve máximos valores de MSPA e de MFPA na dose de $6 \mathrm{~kg} / \mathrm{m}^{3}$, para a espécie Araucaria agustifolia e para a Ocotea odorifera foi nas doses de 6 e $9 \mathrm{~kg} \mathrm{~m}^{-3}$ de FLL.

Avaliando Eucalyptus globulus sob fertilização NPK, Pezzutti et al. (1999) concluem que os máximos crescimentos em altura, diâmetro do colo, massa seca da parte aérea, massa seca do sistema radicular e o número de folhas foram obtidos no intervalo de doses de 6,7 a $7,5 \mathrm{~kg} \mathrm{~m}^{-3}$ de substrato.

Binotto (2007) estudou a relação entre as variáveis de crescimento e o IQD em eucalipto e pinus, e concluiu que independente da espécie avaliada, a BSR é a variável que apresenta maior efeito direto e indireto nas demais variáveis, afetando o IQD. Constitui-se na principal variável a ser estudada e indica realmente a qualidade da muda.
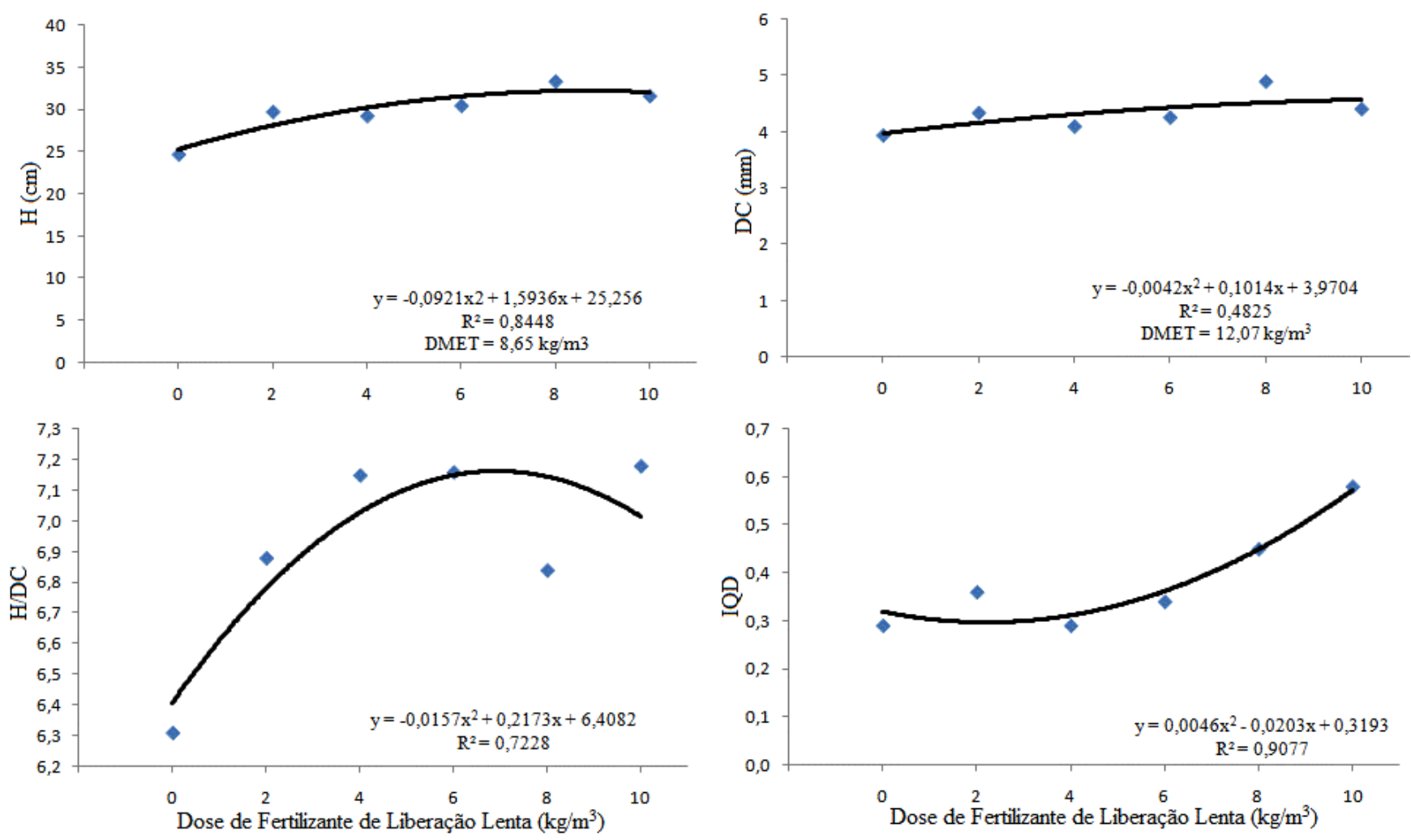

Figura 1. Altura da parte aérea (H), diâmetro do colo (DC), relação altura e diâmetro do colo (H/DC) e índice de qualidade de Dickson (IQD) em função da dose de fertilizante de liberação lenta utilizada para a produção de mudas de paricá. 
Gomes \& Paiva (2004) ratificam que o peso de biomassa seca da parte aérea indica a rusticidade e correlaciona-se diretamente com a sobrevivência e desempenho inicial das mudas após o plantio em campo.

\section{Aspectos econômicos da fertilização}

Embora existam trabalhos sobre a importância da fertilização do paricá em suas fases de crescimento e desenvolvimento, há poucos estudos econômicos que demonstrem as vantagens e desvantagens da utilização de FLL em detrimento do uso de fertilizantes minerais

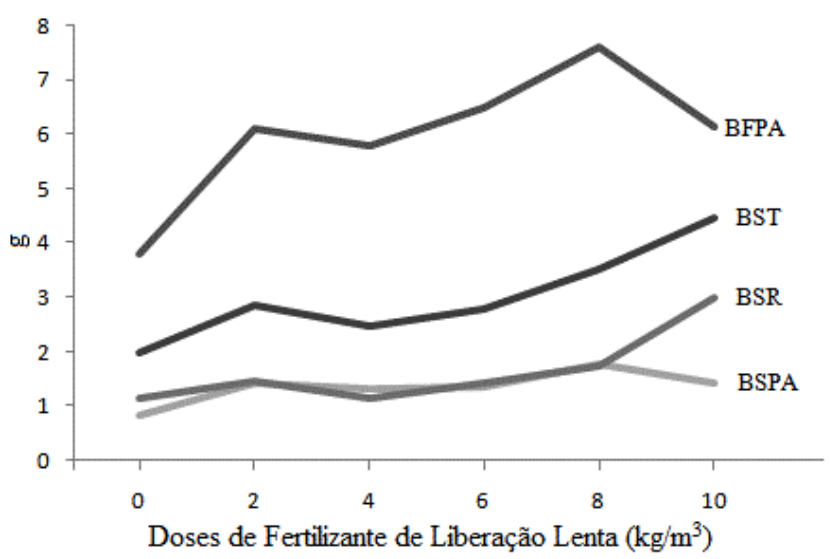

Figura 2. Comportamento das variáveis biomassa fresca da parte aérea (BFPA), biomassa seca total (BST), biomassa seca da parte aérea (BSPA) e biomassa seca da raiz (BSR) em função da dose de fertilizante de liberação lenta utilizada para a produção de mudas de paricá.

comerciais. O ponto mais impactante contra a utilização do FLL é o custo de aquisição do insumo, cotado a aproximadamente $\mathrm{R} \$ 460,00$ a saca de $25 \mathrm{~kg}$ do produto Basacote $6 \mathrm{M}$, enquanto o fertilizante comercial, por exemplo, com formulação comercial NPK 5-15-10, tem custo de aquisição de $\mathrm{R} \$ 47,00$ a saca de $50 \mathrm{~kg}$. Essa diferença de preços impacta negativamente a análise de investimentos da atividade de adubação com FLL.

Como aspectos econômicos positivos da utilização do FLL na cultura do paricá destacam-se a menor quantidade de fertilizantes necessária e a redução ou mesmo a eliminação de adubação de cobertura no viveiro.

Para Souza et al. (2003), a quantidade de fertilizantes comerciais recomendada no substrato de produção de mudas oscila entre 2 a $3 \mathrm{~kg}$ de NPK 15-30-15, com $20 \%$ de esterco decomposto e calagem com $6 \mathrm{~kg}$ de calcário, por metro cúbico de substrato, na ocasião da repicagem.
Em condições de campo, Marques (1990) obteve resultados satisfatórios no desenvolvimento de paricá em plantio definitivo aplicando $50 \mathrm{~g}_{\text {planta }}{ }^{-1}$ de NPK na formulação de NPK 15-25-12 direto na cova, e 130 g planta ${ }^{-1}$ de NPK da mesma formulação em adubação de cobertura após 60 dias do plantio.

Para exemplificar, considerando uma dosagem de $5 \mathrm{~kg}$ de fertilizante convencional em formulação comercial NPK 5-15-10 por $\mathrm{m}^{3}$ de substrato, suficiente para o enchimento de aproximadamente 2.500 tubetes de $180 \mathrm{~cm}^{3}$, e produção de 2.250 mudas de paricá, com perdas no processo de produção de $10 \%$, bem como $112,5 \mathrm{~kg}\left(50 \mathrm{~g} \mathrm{planta}^{-1}\right)$ de adubação de base na cova e $292,5 \mathrm{~kg}\left(130 \mathrm{~g} \mathrm{planta}^{-1}\right)$ em adubação de cobertura após 60 dias do plantio, o consumo de adubo seria equivalente a $410 \mathrm{~kg}$, sendo o custo com fertilização deste sistema de produção de cerca de $\mathrm{R} \$ 390,00$. Já ao utilizar o FLL, a dosagem seria de $8,5 \mathrm{~kg}$ por $\mathrm{m}^{3}$ de substrato, suficiente para a produção das mesmas 2.250 mudas de paricá, e uma adubação de base na cova de $45 \mathrm{~kg}$ (20 g planta $\left.^{-1}\right)$. Nesse caso, a quantidade e o custo total de adubo são de aproximadamente $54 \mathrm{~kg}$ e $\mathrm{R} \$ 990,00$, respectivamente.

Dessa maneira considerando somente o valor da aquisição e a quantidade do produto utilizado, o custo da produção de mudas e as adubações iniciais no plantio com uso de FLL seria duas vezes e meia maior quando comparado a adubação convencional, porém a análise somente considera o valor de aquisição desprezando outros custos importantes na produção de mudas como o de armazenamento e transporte do insumo, mão de obra e a legislação trabalhista entre outros aspectos.

A quantidade de adubos convencionais seria 7,6 vezes a mais que o FLL requerendo gasto em transporte e locais maiores e adequadas de armazenamento. Além disso, a utilização de fertilizantes comerciais exige atividades adicionais de adubação de cobertura em viveiro e campo. Essas atividades geram despesas pelo uso da mão de obra, incluindo salário e encargos sociais, e de equipamentos, composto pelos custos de aquisição, depreciação, manutenção entre outros. Outros fatores com impacto econômico também devem ser considerados na escolha entre fertilização convencional ou de liberação lenta, tais como: (a) qualidade das mudas produzidas e consequente valorização na venda; (b) índice de sobrevivência em campo, que implica em menor custo de replantio; (c) menor desperdício de adubo; (d) redução do impacto ambiental provocado pela contaminação do sitio e 
do lençol freático por fósforo $\left(\mathrm{P}_{2} \mathrm{O}_{5}\right)$ e nitrato $\left(\mathrm{NO}_{3}^{-}\right)$ provenientes de fertilizantes de elevada solubilidade, visto que as questões ambientais estão se tornando importantes, com tendência de que este fato impacte sobre os custos das atividades.

\section{Conclusão}

As mudas de paricá responderam positivamente ao uso do fertilizante de liberação lenta (FLL), e recomenda-se dosagens s entre 8,65 a $12,07 \mathrm{~kg} \mathrm{~m}^{-3}$ para formação de mudas de boa qualidade.

Os custos e quantidades da FLL foram elevados porém uma análise econômica e silvicultural considerando todos os aspectos envolvidos na produção de mudas e estabelecimento da espécie em campo são necessário para inferir com segurança quanto a sua utilização na produção de mudas e implantação inicial do reflorestamento com o paricá.

\section{Referências}

ANUÁRIO ESTATÍSTICO DA ABRAF 2011: ano base 2010. Brasília, DF: Associação Brasileira de Produtores de Florestas Plantada, 2011. 130 p.

AlMEIDA, S. L.; MAIA, N.; ORTEGA, A. R.; ANGElO, A. C. Crescimento de mudas de Jacaranda puberula Cham. em viveiro submetidas a diferentes níveis de luminosidade. Ciência Florestal, Santa Maria, RS, v. 15, n. 3, p. 323-329, 2005.

BARBIZAN, E. L.; LANA, R. M. Q.; MENDONÇA, F. C.; MELO, B.; SANTOS, C. M.; MENDES, A. F. Produção de mudas de cafeeiro em tubetes associada a diferentes formas de aplicação de fertilizantes. Ciência Agrotécnica, Lavras, n. especial, p. 1471-1480, dez. 2002.

BINOTTO, A. F. Relação entre variáveis de crescimento e o índice de qualidade de Dickson em mudas de Eucalyptus grandis W. Hill ex Maid e Pinus elliottii var. elliottii - Engelm. 2007. 53 f. Dissertação (Mestrado em Engenharia Florestal) - Universidade Federal de Santa Maria, Santa Maria, RS.

BOCKMAN, O. C.; OLFS, H. W. Fertilizers, agronomy and $\mathrm{N}_{2} \mathrm{O}$. Nutrient Cycling in Agroecosystems, Dordretcht, v. 52, n. 2/3, p. 165-170, 1998.

CARnEIRO, J. G. de A. Produção e controle de qualidade de mudas florestais. Curitiba: UFPR/FUPEF; Campos: UENF, 1995. $451 \mathrm{p}$.

CARVALHO, P. E. R. Espécies arbóreas brasileiras. Brasília, DF: Embrapa Informação Tecnológica; Colombo: Embrapa Florestas, 2003. v. 1.

DICKSON, A.; LEAF, A. L.; HOSNER, J. F. Quality appraisal of white spruce and white pine seedling stock in nurseries. Forest Chronicle, v. 36, p. 10-13, 1960.
FONSECA, E. P. Padrão de qualidade de mudas de Trema micrantha (L.) Blume., Cedrela fissilis Vell. E Aspidosperma polyneuron Müll. Arg. produzidas sob diferentes períodos de sombreamento. 2000. 113 f. Tese (Doutorado em Ciências Agrárias) - Universidade Estadual Paulista, Jaboticabal.

GOMES, J. M.; PAIVA, H. N. Viveiros florestais: propagação sexuada. 3. ed. Viçosa, MG: UFV, 2004. 116 p.

GONÇALVES, J. L.; POGGIANI, F. Substratos para produção de mudas florestais. In: CONGRESSO LATINO-AMERICANO DE CIÊNCIA DO SOLO, 13, 1996, Águas de Lindóia Anais... Águas de Lindóia: Sociedade Latino-Americana de Ciência do Solo, 1996.

HUNT, G. A. Effect of styroblock design and cooper treatment on morphology of conifer seedlings. In: TARGET SEEDLING SYMPOSIUM, MEETING OF THE WESTERN FOREST NURSERY ASSOCIATIONS, GENERAL TECHNICAL REPORT RM-200, 1990, Roseburg. Proceedings... Fort Collins: United States Departament of Agriculture, Forest Service, 1990. p. 218-222.

JOSE, A. C.; DAVIDE, A. C.; OLIVEIRA, S. L. Efeito do volume do tubete, tipo e dosagem de adubo na produção de mudas de aroeira (Schinus terebenthifolia RADDI). Agrarian, Dourados, v. 2, n. 3, p. 73-86, jan./mar. 2009.

LANG, A. Efeitos da aplicação de fertilizante de liberação lenta no estabelecimento de mudas de ipê roxo e angico branco em área de domínio ciliar. 1998. 70 f. Dissertação (Mestrado em Agronomia) - Universidade Estadual do Oeste do Paraná, Marechal Cândido Rondon.

LANZA, T. C. L.; MOTA, P. E. F. da; LACERDA, M. P. C.; CARVALHO, J. G. de. Crescimento inicial do paricá (Schizolobium amazonicum) afetado pela omissão de macronutrientes, em solução nutritiva. In: REUNIÃO BRASILEIRA DE FERTILIDADE DE SOLO E NUTRIÇÃO DE PLANTAS 22., 1996, Manaus. Resumos expandidos. Manaus: Universidade do Amazonas, 1996a. p. 363364.

LANZA, T. C. L.; LACERDA, M. P. C.; MOTA, P. E. F. da; CARVALHO, J. G. de; GUALBERTO, V. Sintomas de deficiências nutritionais em paricá (Schizolobium amazonicum), cultivado em solução nutritiva. In: REUNIÃO BRASILEIRA DE FERTILIDADE DE SOLO E NUTRIÇÃO DE PLANTAS 22., 1996, Manaus. Resumos expandidos. Manaus: Universidade do Amazonas, 1996b. p. 367-368.

MARQUES, L. C. T. Comportamento inicial de paricá, tatajuba e eucalipto, em plantio consorciado com milho e capim-marandu, em Paragominas, Pará. Viçosa: UFV, 1990. 92 p.

MARQUES, T. C. L. L. S. M.; CARVALHO, J. G. de; LACERDA, M. P. C., MOTA, P. E. F. da. Exigências nutricionais do paricá (Schizolobium amazonicum, Herb.) na fase de muda. Cerne, Lavras, v. 10, n. 2, p. 167-183, jul./dez. 2004.

MENDONÇA, V.; TOSTA, M. S.; MACHADO, J. R.; GOULART JÚNIOR, S. A. R.; TOSTA, J. S.; BISCARO, G. A. Fertilizante de liberação lenta na formação de mudas de maracujazeiro "amarelo". Ciência e Agrotecnologia, Lavras, v. 31, n. 2, p. 344-348, mar./ abr. 2007.

Pesq. flor. bras., Colombo, v. 33, n. 75, p. 227-234, jul./set. 2013 
MORAES NETO, S. P.; GONÇALVES, J. L. M.; ARTHUR JR, J. C.; DUCATTI, F; AGUIRRE JUNIOR, J. H. Fertilização de mudas de espécies arbóreas nativas e exóticas. Revista Árvore, Viçosa, MG, v. 27, n. 2, p. 129-137, 2003a.

MORAES NETO, S. P.; GONÇALVES, J. L. M.; RODRIGUES, C. J.; GERES, W. L. A.; DUCATTI, F; AGUIRRE JR, J. H. Produção de mudas de espécies arbóreas nativas com combinações de adubos de liberação controlada e prontamente solúveis. Revista Árvore, Viçosa, MG, v. 27, n. 6, p. 779-789, 2003b.

PEZZUTTI, R. V.; SCHUMACHER, M. V.; HOPPE, J. M. Crescimento de mudas de Eucalyptus globulus em resposta à fertilização NPK. Ciência Florestal, Santa Maria, RS, v. 9, n. 2, p. 117-125, 1999.

ROSSA, Ü. B.; ANGELO, A. C.; NOGUEIRA, A. C.; REISSMANN, C. B.; GROSSI, F.; RAMOS, M. R. Fertilizante de liberação lenta no crescimento de mudas de Araucaria angustifolia e Ocotea odorifera. Revista Floresta, Curitiba, v. 41, n. 3, p. 491-500, jul./set. 2011.

SCIVITTARO, W. B.; OLIVEIRA, R. P.; RADMANN, E. B. Doses de fertilizante de liberação lenta na formação do porta-enxerto 'Trifoliata'. Revista Brasileira de Fruticultura, Jaboticabal, v. 26, n. 3 , p. $520-523,2004$.
SERRANO, L. A. L.; MARINHO, C. S.; CARVAlHO, A. J. C. de; MONNERAT, P. H. Efeito de sistemas de produção e doses de adubo de liberação lenta no estado nutricional de porta-enxerto cítrico. Revista Brasileira de Fruticultura, Jaboticabal, v. 26, n. 3, p. 524-528, dez. 2004.

SERRANO, L. A. L.; MARINHO, C. S.; BARROSO, D. G.; CARVALHO, A. J. C. de. Sistema de blocos prensados e doses de adubo de liberação lenta na formação de porta-enxerto cítrico. Ciência Rural, Santa Maria, RS, v. 36, n. 2, p. 441-447, mar./abr. 2006.

SHAVIV, A. Preparation methods and release mechanisms of controlled release fertilizers: agronomic efficiency and environmental significancy. York : International Fertiliser Society, 1999. p. 1-35. (Proceedings International Fertiliser Society, n. 41).

SOUZA, C. R. de; ROSSI, L. M. B.; AZEVEDO, C. P. de; VIEIRA, A. H. Paricá: Schizolobium parahyba var. amazonicum (Huber x Ducke) Barneby. Manaus: Embrapa Amazônia Ocidental, 2003. 12 p. (Embrapa Amazônia Ocidental. Circular técnica, 18).

WENDLING, I.; DUTRA, L. F.; GROSSI, F. Produção de mudas de espécies lenhosas. Colombo: Embrapa Florestas, 2006. (Embrapa Florestas. Documentos, 130). 